\title{
PREPARO DO SOLO, IRRIGAÇÃO POR ASPERSÃO E RENDIMENTO DE ENGENHO DO ARROZ DE TERRAS ALTAS
}

\author{
Orivaldo Arf'*; Ricardo Antonio Ferreira Rodrigues ${ }^{1}$; Marco Eustáquio de Sá1; Carlos Alexandre \\ Costa Crusciol2; Júlio Cesar dos Reis Pereira ${ }^{1}$ \\ ${ }^{1}$ Depto. de Fitotecnia, Tecnologia de Alimentos e Sócio-Economia - FE/UNESP - C.P. 31 - CEP: 15385-000 - Ilha \\ Solteira, SP \\ ${ }^{2}$ Depto. de Agricultura e Melhoramento Vegetal - FCA-UNESP, C.P. 237 - CEP: 18603-970 - Botucatu, SP. \\ *Autor correspondente <arf@agr.feis.unesp.br>
}

\begin{abstract}
RESUMO: O rendimento de engenho obtido após o beneficiamento industrial é um parâmetro importante durante a fase de comercialização do arroz e pode ser influenciado pelas práticas culturais realizadas durante o período de cultivo. O presente trabalho teve como objetivo avaliar o rendimento de benefício, rendimento de inteiros e grãos quebrados de cultivares de arroz de sequeiro em função do preparo do solo e da irrigação por aspersão na região de Selvíria - MS, durante os anos agrícolas de 1997/98 e 1998/99. O solo do local é do tipo Latossolo Vermelho álico, textura argilosa e os tratamentos consistiram na combinação de três cultivares de arroz (IAC 201, Carajás e Guarani), com três sistemas de preparo do solo (arado de aiveca + grade niveladora, escarificador + grade niveladora e grade pesada + grade niveladora) e três níveis de irrigação por aspersão (sequeiro e duas lâminas de água), com quatro repetições. O cultivar IAC 201 apresenta maior rendimento de benefício e o Carajás destaca-se dos demais em rendimento de inteiros; os diferentes sistemas de preparo utilizados praticamente não interferem no rendimento de engenho; a irrigação por aspersão aumenta o rendimento de benefício e o rendimento de inteiros, principalmente em ano com ocorrência de veranico. Palavras-chave: lâminas de água, grade pesada, arado de aiveca, escarificador, cultivares
\end{abstract}

\section{TILLAGE, SPRINKLER IRRIGATION AND HULLING YIELD OF DRYLAND RICE}

\begin{abstract}
The mill revenue obtained after industrial rice processing is an important parameter for the comercialization of rice and it can be influenced by management pratices accomplished during cultivation. To evaluate the hulling yield, undamaged grains and broken grains of three dryland rice cultivars were studied in relation to soil preparation and sprinkler irrigation. A field experiment was carried out in Selvíria, MS, Brazil on a Typic Haplustox. Treatments consisted of the combination of the three cultivars of dryland rice (IAC 201, Carajás and Guarani), with three soil preparation systems (aiveca plow + leveling bars, scared + leveling bars and heavy bars + leveling bars) and three sprinkler irrigation levels (dry and two depths of water), with four replications. The IAC 201 cultivar presented a larger hulling yield and Carajás stands out for undamaged grains; the different systems of soil preparation did not interfere in the hulling yield; sprinkler irrigation increases hulling yield, and undamaged grains, mainly in years with dry periods.

Key words: water depth, moldboard plow, disking chisel, disk harrow, rice cultivars
\end{abstract}

\section{INTRODUÇÃO}

O sistema de cultivo de arroz predominante no Brasil é o sequeiro em terras altas e, na maioria das regiões onde se pratica esta modalidade, o risco de perda em função da possibilidade de ocorrência de "veranico" é grande. Uma das alternativas apontadas para minimizar o risco de perda da cultura, aumentar a produtividade e melhorar a qualidade dos grãos produzidos, tem sido o uso da irrigação por aspersão. Outro aspecto importante, é que com a eliminação do risco de perder a cultura por falta de água, o agricultor sente-se mais estimulado a utilizar melhor tecnologia e conseqüentemente, aumentar a produtividade da cultura e a qualidade do produto colhido.

$O$ rendimento de inteiros significa a quantidade de grãos inteiros obtida após o beneficiamento industrial e é um dos parâmetros mais importantes para determinar o valor de comercialização do arroz (Oliveira et al., 1998).
A presença de grãos quebrados em um lote de arroz é uma característica indesejável, pois diminui a qualidade e o valor comercial do produto. Além da redução do valor econômico, pode ocorrer também, a diminuição da quantidade total de grãos descascado, ou seja, o rendimento de benefício, pois fração de grãos pode ser eliminada junto com as cascas (Crusciol et al., 1999).

Arf (1993), estudando as características agronômicas e os componentes do rendimento de engenho dos cultivares Rio Paranaíba, Araguaia, Guarani e Carajás sob irrigação por aspersão, com diferentes densidades populacionais, doses e épocas de aplicação de nitrogênio em cobertura, verificou que os cultivares Carajás, Rio Paranaíba e Araguaia podem ser recomendados para as condições de sequeiro com irrigação por aspersão. Já o cultivar Guarani apresentou alto índice de acamamento, menor rendimento de inteiros e maior quantidade de grãos quebrados. 
Utilizando os cultivares IAC 201 e Carajás em cultivo de sequeiro e irrigado por aspersão aplicando diferentes lâminas de água, Nakao (1995) verificou que ambos os cultivares apresentaram maior rendimento de benefício e de inteiros na presença da irrigação e o cultivar Carajás apresentou maior produtividade de grãos comparativamente ao IAC 201.

Estudos realizados por Oliveira et al. (1997) no município de Selvíria (MS) utilizando os cultivares Caiapó, Araguaia, IAC 201 e Carajás cultivados em condições de sequeiro e irrigados por aspersão com diferentes densidades de semeadura, mostraram que a presença ou ausência da irrigação não interfere no rendimento de benefício dos cultivares Caiapó, IAC 201 e Carajás. Já os cultivares IAC 201 e Carajás apresentaram maior rendimento de inteiros na presença de irrigação.

Crusciol et al. (1999) também no município de Selvíria (MS) estudando diferentes espaçamentos entre fileiras e densidade de semeadura para o cultivar IAC 201, obtiveram bons valores para o rendimento de benefício $(72,3 \%)$ e de grãos inteiros $(55 \%)$, nas condições de sequeiro. Já Crusciol (2001) avaliando a influência da disponibilidade hídrica sobre o crescimento radicular, nutrição e desenvolvimento dos cultivares IAC 201 e Carajás, concluiu que a menor disponibilidade hídrica reduz o crescimento radicular do arroz de terras altas tendo como conseqüência menor nutrição e produtividade de grãos e, a maior produtividade de grãos do cultivar Carajás pode estar associada ao maior crescimento radicular em profundidade.

A literatura ainda é escassa em trabalhos envolvendo o cultivo irrigado por aspersão e diferentes modalidades de preparo do solo influenciando os componentes do rendimento de grãos do arroz. Assim, o presente trabalho teve como objetivo avaliar o rendimento de benefício, de inteiros e grãos quebrados dos cultivares IAC 201, Guarani e Carajás em função do preparo do solo e da irrigação por aspersão.

\section{MATERIAL E MÉTODOS}

O trabalho foi conduzido nos anos agrícolas de 1997/98 e 1998/99, em área experimental da Faculdade de Engenharia de Ilha Solteira - UNESP, no município de Selvíria (MS) situado a $51^{\circ} 22^{\prime}$ de longitude Oeste e $20^{\circ} 22^{\prime}$ de latitude Sul, com altitude de $335 \mathrm{~m}$. O solo do local é do tipo Latossolo Vermelho álico, textura argilosa. A precipitação média anual é de $1370 \mathrm{~mm}$, a temperatura média anual é de $23,5^{\circ} \mathrm{C}$ e a umidade relativa do ar média anual entre 70 e $80 \%$.

Antes da instalação do experimento foram coletadas amostras de solo da área experimental a 0,20 $\mathrm{m}$ e realizada a análise química para fins de fertilidade, de acordo com a metodologia proposta por Raij \& Quaggio (1983), apresentando os seguintes resultados: $\mathrm{pH}\left(\mathrm{CaCl}_{2}\right)=5,8 ; 22 \mathrm{~g} \mathrm{~kg}^{-1}$ de M.O.; $15 \mathrm{mg} \mathrm{dm}^{-3}$ de P Scientia Agricola, v.59, n.2, p.321-326, abr./jun. 2002 (resina); 1,$0 ; 34 ; 12$ e $20,0 \mathrm{~m} \mathrm{~mol}_{\mathrm{c}} \mathrm{dm}^{-3}$ de $\mathrm{K}, \mathrm{Ca}, \mathrm{Mg} \mathrm{e}$ $\mathrm{H}+\mathrm{Al}$, respectivamente, e $70 \%$ de saturação por bases.

A capacidade de retenção de água no solo foi determinada utilizando-se uma unidade de sucção segundo Grohmann (1960) na faixa de 0,002 a 0,01 MPa, aparelhos de pressão de placa porosa recomendados por Richards \& Fireman (1943) na faixa de 0,033 a 0,101 $\mathrm{MPa}$, e a membrana de Richards (1947) na faixa de 0,101 a $1,520 \mathrm{MPa}$.

O delineamento experimental foi em blocos casualizados com um esquema fatorial $3 \times 3 \times 3$, totalizando 27 tratamentos constituídos pela combinação de três cultivares de arroz de sequeiro (IAC 201, Carajás e Guarani), com três sistemas de preparo do solo (escarificador + grade niveladora, arado de aiveca + grade niveladora e grade pesada + grade niveladora) e três níveis de irrigação por aspersão (não irrigado, lâmina 1 e lâmina 2), com quatro repetições.

As parcelas foram constituídas por sete linhas de $6,0 \mathrm{~m}$ de comprimento espaçadas $0,40 \mathrm{~m}$, totalizando uma área de $16,8 \mathrm{~m}^{2}$, sendo a área útil constituída pelas 5 linhas centrais, desprezando-se $0,5 \mathrm{~m}$ em ambas as extremidades de cada linha. Deixou-se um espaço livre de $6,0 \mathrm{~m}$ entre as parcelas.

Os cultivares IAC 201, Carajás e Guarani apresentam ciclo curto e são recomendados para cultivo em terras altas no estado de Mato Grosso do Sul. O Carajás apresenta resistência ao acamamento, maior produtividade e sua melhor arquitetura de plantas permitem semeaduras em espaçamentos menores, contribuindo assim como coadjuvante no controle de plantas daninhas. O Guarani possui altura média de 100 $\mathrm{cm}$, podendo acamar quando cultivado em solo de alta fertilidade e com boas condições pluviométricas, já o cultivar IAC 201 apresenta produtividade ligeiramente inferior aos cultivares Carajás e Guarani, porém apresenta excelente tipo de grãos, longos e finos, translúcidos e com alto rendimento de grãos inteiros no beneficiamento, com centro branco insignificante e com excelentes qualidades culinárias (Bazoni et al, 1995). Nas condições edafoclimáticas do município de Selvíria (MS), os cultivares tem apresentado praticamente o mesmo número de dias da emergência ao florescimento e da emergência à colheita (Nakao, 1995; Oliveira et al., 1997 e Arf et al., 1998). Os cultivares IAC 201 e Carajás apresentam comportamento contrastante quanto a resposta à irrigação por aspersão. Oliveira (1994), no município de Selvíria (MS), verificou que a irrigação por aspersão propiciou incrementos de 38 e 133\% na produtividade de grãos dos cultivares Carajás e IAC 201, respectivamente. A autora verificou em campo, nas condições de ausência de irrigação, que em períodos de baixa disponibilidade hídrica no solo, o cultivar Carajás mantinha um aspecto visual de melhor suprimento de água comparativamente a outros cultivares utilizados. $\mathrm{O}$ grande incremento de produtividade obtido com o uso da irrigação no cultivar IAC 201, talvez possa ser explicado 
pela origem do cultivar, ou seja, obtido pelo cruzamento entre os cultivares IAC 165 (recomendado para cultivo em sequeiro ou terras altas) e Labelle (recomendado para cultivo irrigado por inundação), levando à obtenção de um cultivar com menor tolerância à falta de água no solo.

Nos tratamentos irrigados, o fornecimento de água foi realizado através de um sistema fixo de irrigação convencional por aspersão com precipitação de $3,3 \mathrm{~mm}$ hora $^{-1}$ nos aspersores e foi considerada a água proveniente da precipitação. A precipitação pluvial foi determinada em um pluviômetro Ville de Paris, instalado próximo à área experimental.

A evaporação de água (ECA) foi obtida diariamente do tanque classe $\mathrm{A}$ instalado no posto agrometeorológico da área experimental. $O$ coeficiente do tanque classe $A(\mathrm{Kp})$ utilizado foi o proposto por Doorenbos \& Pruitt (1976), sendo que este é função da área circundante, velocidade do vento e umidade relativa do ar. Os coeficientes da cultura (Kc), foram diferentes para os períodos que sucederam a emergência, levandose em consideração o valor máximo do $K c=1,0$, referente ao período total de crescimento adapatado de Doorenbos \& Kassan (1979). A lâmina de água L1 consistiu na utilização de três coeficientes de cultura (Kc), distribuídos em quatro períodos compreendidos entre a emergência e a colheita. Na fase vegetativa, foi utilizado um valor de 0,2 , na fase reprodutiva dois coeficientes de cultura $(\mathrm{Kc})$, o inicial de 0,35 e o final de 0,50 e na fase de maturação os mesmos coeficientes, invertendo os valores. A lâmina de água L2 foi caracterizada por utilizar o dobro dos valores de Kc para os mesmos períodos da lâmina L1 e o cultivo sem irrigação contou somente com a água proveniente da chuva. O controle da irrigação foi feito inicialmente com a capacidade de armazenamento de água disponível máxima $(16,8 \mathrm{~mm})$, subtraindo-se sucessivamente o valor da evapotranspiração máxima até que o total de água atingia o valor da água disponível do solo $(10,0 \mathrm{~mm})$, considerando a profundidade efetiva do sistema radicular de $0,20 \mathrm{~m}$.

O preparo do solo, dependendo do tratamento, foi realizado através de escarificador, arado de aiveca ou grade aradora e duas gradagens niveladoras, sendo a segunda gradagem niveladora realizada as vésperas da semeadura.

Após a abertura mecanizada dos sulcos realizouse manualmente a adubação básica com $250 \mathrm{~kg} \mathrm{ha}^{-1} \mathrm{da}$ fórmula 8-28-16 +0,5\% $\mathrm{Zn}+0,3 \% \mathrm{~B}$. Para o cálculo da quantidade de fertilizante, levou-se em consideração a característica química do solo, a produtividade esperada e as recomendações de Raij et al. (1996). Aplicou-se o inseticida granulado (carbofuran $-1.500 \mathrm{~g} \mathrm{ha}^{-1}$ de i.a.) no sulco, fazendo-se então a semeadura manual (07.11.97 e 05.11.98), utilizando-se número de sementes necessárias para se obter um estande ao redor de 120 plantas $\mathrm{m}^{-2}$. Após a cobertura das sementes com uma camada de 0,04 a 0,05 m de terra, aplicou-se o herbicida em pré-emergência (oxadiazon - $1.000 \mathrm{~g} \mathrm{ha}^{-1}$ de i.a.).
Aos 40 dias após a emergência das plantas realizou-se a adubação de cobertura com $30 \mathrm{~kg} \mathrm{ha}^{-1}$ de $\mathrm{N}$ na forma de sulfato de amônio.

Quando aproximadamente $90 \%$ das panículas apresentavam grãos com coloração típica de maduros realizou-se a colheita das linhas centrais manualmente. Em seguida foi realizada a secagem ao sol, durante um a dois dias e posteriormente a trilha mecânica em trilhadeira de parcela.

Foi coletada uma amostra de 100 gramas de arroz em casca, de cada parcela, a qual foi processada em engenho de prova (SUZUKI), modelo MT, por 1 minuto; em seguida os grãos brunidos polidos foram pesados e o valor encontrado foi considerado como rendimento de benefício, com os dados expressos em porcentagem. Posteriormente, os grãos brunidos foram colocados no "trieur" número 2 e a separação dos grãos foi processada por 30 segundos; os grãos que permaneceram no "trieur" foram pesados, obtendo-se o rendimento de inteiros e os demais, grãos quebrados, ambos expressos em porcentagem.

\section{RESULTADOS E DISCUSSÃO}

No ano agrícola 1997/98 houve menor precipitação mensal a partir do mês de dezembro, em relação ao ano agrícola 1998/99 (Tabela 1). O período de florescimento no primeiro ano de cultivo ocorreu de 22 a 31 de janeiro nos tratamentos irrigados e de 2 a 6 de fevereiro no tratamento de sequeiro, período esse de baixa precipitação e também agravado pela falta de água no período de 3 a 11 dias antes do florescimento, onde a planta apresenta maior suscetibilidade à falta de água. O florescimento no segundo ano de cultivo ocorreu de 21 a 26 de janeiro em todos os tratamentos, e no período de maior sensibilidade, antes do florescimento, houve boa disponibilidade de água para a cultura.

No primeiro ano de cultivo o rendimento de benefício sofreu influência de todos os parâmetros estudados bem como de suas interações (Tabela 2). $\mathrm{Na}$ Tabela 3 está apresentado o desdobramento da interação cultivar x preparo do solo. O IAC 201 apresentou maior rendimento de inteiros no preparo realizado com aiveca e escarificador. Quanto aos dados de preparo do solo dentro de cultivar, observou-se efeito significativo apenas para o cultivar Carajás, onde o preparo com escarificador apresentou maior rendimento de benefício. Este resultado evidencia o efeito de cultivar, onde o Carajás se apresentou mais exigente ao tipo de preparo do solo do que os cultivares IAC 201 e Guarani. $\mathrm{O}$ adequado preparo do solo favorece o desenvolvimento radicular e a absorção de nutrientes e por conseguinte o desenvolvimento das plantas. $\mathrm{O}$ uso de escarificador favorece a manutenção do grau de agregação do solo proporcionando uma maior aeração, absorção de água e nutrientes, havendo uma pequena quebra de estrutura apenas na camada superficial do solo. Este fato pode 
Tabela 1 - Precipitação -P e lâmina de água -L1 e L2, em intervalos de dez dias, durante o período de condução do experimento. Anos agrícolas de 1997/1998 e 1998/1999. Selvíria (MS).

\begin{tabular}{|c|c|c|c|c|c|c|}
\hline \multirow{3}{*}{ Decêndio } & \multicolumn{2}{|c|}{ Sequeiro } & \multicolumn{4}{|c|}{ Irrigado } \\
\hline & $1997 / 1998$ & $1998 / 1999$ & $1997 / 1998$ & $1998 / 1999$ & $1997 / 1998$ & 1998/1999 \\
\hline & \multicolumn{2}{|c|}{$\mathrm{P}$} & \multicolumn{2}{|c|}{ Lâmina-L 1} & \multicolumn{2}{|c|}{ Lâmina-L2 } \\
\hline $20 / 11$ a $29 / 11$ & 64,2 & 19,0 & 8,4 & 7,2 & 12,6 & 26,7 \\
\hline $30 / 11$ a $09 / 12$ & 121,4 & 63,4 & 0,0 & 7,0 & 0,0 & 0,0 \\
\hline $10 / 12$ a $19 / 12$ & 30,4 & 86,0 & 0,0 & 0,0 & 0,0 & 0,0 \\
\hline $20 / 12$ a $29 / 12$ & 15,4 & 117,0 & 14,4 & 6,0 & 33,6 & 6,0 \\
\hline $30 / 12$ a $08 / 12$ & 68,2 & 176,8 & 16,5 & 0,0 & 38,1 & 0,0 \\
\hline 09/01 a 18/01 & 71,1 & 90,7 & 0,0 & 10,3 & 24,6 & 10,3 \\
\hline $19 / 01$ a $28 / 01$ & 22,6 & 51,6 & 20,3 & 16,1 & 50,1 & 37,0 \\
\hline $29 / 01$ a $07 / 02$ & 34,1 & 103,6 & 12,9 & 14,1 & 36,7 & 20,2 \\
\hline $08 / 02$ a $17 / 02$ & 67,6 & 172,6 & 11,8 & 0,0 & 17,3 & 0,0 \\
\hline Total & 495,0 & 880,7 & 84,1 & 60,7 & 212,8 & 100,1 \\
\hline
\end{tabular}

Tabela 2 - Rendimento de engenho de cultivares de arroz em terras altas em função de diferentes preparos do solo e lâminas de água aplicadas através de irrigação por aspersão. Selvíria (MS), 1997/98 e 1998/99.

\begin{tabular}{|c|c|c|c|c|c|c|c|}
\hline \multirow{2}{*}{ Tratamento } & & \multicolumn{2}{|c|}{ Rendimento de Benefício } & \multicolumn{2}{|c|}{ Rendimento de inteiros } & \multicolumn{2}{|c|}{ Grãos quebrados } \\
\hline & & $97 / 98$ & $98 / 99$ & $97 / 98$ & $98 / 99$ & $97 / 98$ & $98 / 99$ \\
\hline & & -ב---- & - & --- $\%$ & 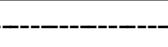 & --------_. & ------ \\
\hline & IAC 201 & $68,57 a$ & $73,20 a$ & $38,35 \mathrm{~b}$ & $50,86 \mathrm{c}$ & $30,20 \mathrm{a}$ & $22,10 \mathrm{a}$ \\
\hline \multirow[t]{3}{*}{ Cultivar } & Carajás & $66,84 \mathrm{~b}$ & $72,58 \mathrm{~b}$ & $45,15 a$ & 57,30 a & $21,65 b$ & $15,24 \mathrm{c}$ \\
\hline & Guarani & $66,62 \mathrm{~b}$ & 73,65 a & $36,59 b$ & $54,07 \mathrm{~b}$ & 29,78 a & $19,39 \mathrm{~b}$ \\
\hline & Aiveca & $66,77 \mathrm{~b}$ & 73,29 & 38,90 & 53,98 & 27,83 & 18,32 \\
\hline \multirow[t]{3}{*}{ Preparo do Solo } & Escarificador & $68,13 a$ & 73,28 & 41,69 & 54,61 & 26,40 & 18,79 \\
\hline & Grade & $67,13 \mathrm{ab}$ & 72,86 & 39,51 & 53,64 & 27,41 & 19,37 \\
\hline & Sequeiro & $63,83 \mathrm{~b}$ & $72,88 \mathrm{~b}$ & $31,99 \mathrm{c}$ & 54,16 & $31,80 \mathrm{a}$ & 18,72 \\
\hline \multirow[t]{5}{*}{ Lâmina de água } & L1 & 68,77 a & $73,03 a b$ & $42,05 \mathrm{~b}$ & 53,99 & $26,68 \mathrm{~b}$ & 18,83 \\
\hline & L2 & 69,43 a & $73,52 a$ & 46,05 a & 54,09 & $23,16 \mathrm{c}$ & 19,19 \\
\hline & Cultivar (C) & $9,91^{* *}$ & $13,04^{* *}$ & $18,19^{* *}$ & $33,15^{\star \star}$ & $27,48^{\star \star}$ & $47,96^{* *}$ \\
\hline & Preparo do Solo $(P)$ & $4,29^{*}$ & $2,79 \mathrm{~ns}$ & $1,91 \mathrm{~ns}$ & $0,78 \mathrm{~ns}$ & $0,64 \mathrm{~ns}$ & $0,74 \mathrm{~ns}$ \\
\hline & Lâmina de água (L) & $81,21^{\text {** }}$ & $5,13^{\star *}$ & $46,71^{* *}$ & $0,02 n s$ & $22,29^{\star \star}$ & $0,25 \mathrm{~ns}$ \\
\hline \multirow[t]{5}{*}{$\mathrm{F}$} & $C \times P$ & $2,52^{\star \star}$ & $1,23 \mathrm{~ns}$ & $1,41 \mathrm{~ns}$ & $1,10 \mathrm{~ns}$ & $0,87 \mathrm{~ns}$ & $1,18 \mathrm{~ns}$ \\
\hline & $C \times L$ & $4,12^{*}$ & $1,37 \mathrm{~ns}$ & $4,22^{\star \star}$ & $2,52 \mathrm{~ns}$ & $5,06^{\star *}$ & $2,56 n s$ \\
\hline & $P \times L$ & $3,27^{*}$ & $1,21 \mathrm{~ns}$ & $1,52 \mathrm{~ns}$ & $0,42 n s$ & $0,56 \mathrm{~ns}$ & $0,46 n s$ \\
\hline & $C \times P \times L$ & $2,76^{\star *}$ & $0,85 \mathrm{~ns}$ & $1,41 \mathrm{~ns}$ & $1,20 \mathrm{~ns}$ & $0,89 \mathrm{~ns}$ & $0,93 \mathrm{~ns}$ \\
\hline & C.V. (\%) & 3,03 & 1,23 & 15,88 & 6,21 & 20,28 & 15,82 \\
\hline
\end{tabular}

Médias seguidas de mesma letra dentro de cada parâmetro (cultivar, preparo do solo e lâmina de água) não diferem estatisticamente pelo teste de Tukey a $5 \%$.

favorecer o desenvolvimento de todos ou de alguns cultivares, o que foi verificado neste trabalho, onde a escarificação foi mais benéfica para o cultivar Carajás. Crusciol (2001) verificou que o cultivar Carajás apresenta maior crescimento radicular em profundidade e no presente trabalho o preparo do solo com escarificador deve ter facilitado ainda mais o crescimento das raizes, permitindo às plantas explorar um maior volume de solo e, consequentemente, propiciar um melhor enchimento de grãos. O efeito genótipo foi verificado por Ciat (1980); Kunze (1985), Arf (1993) e Arf et al. (1998) e Zaratin (2000) que verificaram diferenças de rendimentos de benefício entre cutivares ao estudarem épocas de semeadura e também doses de $\mathrm{K}_{2} \mathrm{O}$, evidenciando que existem épocas de semeaduras mais adequadas, as quais poderão propiciar maturação e colheita em período seco e mais ameno favorecendo a obtenção de grãos de melhor qualidade. O potássio também pode contribuir para a produção de grãos de alta qualidade. Nessa situação há genótipos que se destacam em relação a outros e como exemplo podem ser citados o Rio Paranaiba e Araguaia (Arf, 1993), Araguaia, Caiapó, CNA 7801 e CNA 7800 (Arf et al., 1998) e Confiança (Zaratin, 2000).

O desdobramento da interação cultivar x lâmina de água referente ao rendimento de benefício esta apresentado na Tabela 4 onde pode-se verificar que no tratamento sem irrigação (sequeiro) e lâmina L1 houve destaque para o cultivar IAC 201. Quanto as lâminas de água dentro de cultivar, verifica-se que as lâminas $L 1$ e L2 apresentaram maiores valores para o rendimento de benefício em relação ao tratamento não irrigado para 
todos os cultivares utilizados, o que talvez possa ser explicado pelo fornecimento de água via irrigação ter permitido um melhor enchimento de grãos, aumentando assim o rendimento de benefício. Crusciol (2001) verificou que a menor disponibilidade hídrica reduz 0 crescimento redicular do arroz de terras altas tendo como conseqüência menor nutrição e produtividade de grãos.

O desdobramento da interação preparo do solo $x$ lâmina de água referente ao rendimento de benefício está apresentado na Tabela 5. Através dos dados de preparo de solo dentro de lâmina de água, verifica-se que houve efeito significativo apenas no tratamento sem irrigação, onde o preparo do solo com aiveca propiciou a obtenção de menor valor de rendimento de benefício. Quanto à lâmina de água dentro de preparo de solo os tratamentos L1 e L2 apresentaram maior rendimento de benefício comparativamente ao tratamento sem irrigação no preparo de solo realizado com arado de aiveca e grade aradora. No preparo do solo com escarificador, não houve diferença entre as lâminas de água utilizadas e ausência de irrigação. É provável que o preparo do solo com escarificador tenha criado condições para o desenvolvimento do sistema radicular mais em profundidade e com isso as plantas conseguiram aproveitar água em camadas mais profundas e nutrientes em um volume maior de solo, beneficiando assim o enchimento de grãos. Além disso, o fato de provocar apenas um pequeno revolvimento superficial faz com que o preparo com escarificador preserve a agregação do solo o que favorece absorção de água e nutrientes, além de diminuir a perda de água por evaporação, o que deixa maior quantidade de água disponível para as plantas.

Quanto ao rendimento de inteiros e grãos quebrados (Tabela 2), houve destaque para o cultivar Carajás que apresentou maior rendimento de inteiros e menor percentagem de grãos quebrados nos dois anos de cultivo, concordando com Arf (1993) e Arf et al. (1998). A maior produtividade de grãos do cultivar Carajás está associado ao maior crescimento radicular em profundidade (Crusciol, 2001). O rendimento de inteiros deve ter sido influenciado por essa característica do cultivar. O preparo do solo não interferiu no rendimento de inteiros e grãos quebrados. Já para as lâminas de água utilizadas houve efeito significativo no primeiro ano de cultivo onde o rendimento de inteiros foi crescente do tratamento sequeiro para a lâmina L2, já a percentagem de grãos quebrados apresentou comportamento inverso. O rendimento de inteiros significa a quantidade de grãos inteiros obtida após o beneficiamento industrial e é um dos parâmetros mais importantes para determinar o valor de comercialização (Oliveira et al., 1998). No primeiro ano a disponibilidade de água proveniente das chuvas foi bem inferior ao segundo ano (Tabela 1) e esse deve ter sido o fator decisivo para o comportamento observado para o rendimento de inteiros e grãos quebrados. Estes resultados evidenciam a importância da adequada disponibilidade de água no solo para a boa formação dos grãos. Quantidade de água suficiente favorece a absorção de água e a translocação dos fotoassimilados para os grãos. Grãos bem formados vão apresentar maior resistência aos choques e vibrações proporcionadas pela colheita e pelo beneficiamento, assim, obtem-se um maior rendimento de inteiros, fato este verificado no presente trabalho.

O desdobramento da interação cultivar x lâmina de água referente ao rendimento de inteiros está apresentado na Tabela 6. Para as lâminas $L 1$ e $L 2$ houve destaque para o cultivar Carajás. Quanto a lâmina de água dentro de cultivar, pode-se observar que as lâminas L1 e L2 apresentaram maior rendimento de inteiros comparativamente ao tratamento sem irrigação para todos os cultivares utilizados.

Quanto aos grãos quebrados, o desdobramento da interação cultivar x lâmina de água está apresentado na Tabela 7. O cultivar Carajás apresentou menor percentagem de grãos quebrados em todas as lâminas

Tabela 3 - Desdobramento da interação cultivar x preparo de solo da análise de variância referente ao rendimento de benefício (\%). 1997/98.

\begin{tabular}{llcl}
\hline \multirow{2}{*}{ Cultivar } & \multicolumn{3}{c}{ Preparo do solo } \\
\cline { 2 - 4 } & Aiveca & Escarificador & Grade \\
\hline IAC 201 & $68,52 \mathrm{a}$ & $69,10 \mathrm{a}$ & 68,09 \\
Carajás & $65,57 \mathrm{bB}$ & $68,73 \mathrm{aA}$ & $66,22 \mathrm{~B}$ \\
Guarani & $66,22 \mathrm{~b}$ & $66,55 \mathrm{~b}$ & 67,08 \\
\hline
\end{tabular}

Médias seguidas de letras diferentes, minúscula na coluna e maiúscula na linha, diferem estatisticamente, pelo teste de Tukey a $5 \%$.

Tabela 4 - Desdobramento da interação cultivar x lâmina de água da análise de variância referente ao rendimento de benefício (\%). 1997/98.

\begin{tabular}{lccc}
\hline \multirow{2}{*}{ Cultivar } & \multicolumn{3}{c}{ Lâmina de água } \\
\cline { 2 - 4 } & Sequeiro & L1 & L2 \\
\hline IAC 201 & $66,23 \mathrm{aB}$ & $70,02 \mathrm{aA}$ & $69,47 \mathrm{~A}$ \\
Carajás & $62,46 \mathrm{bB}$ & $68,95 \mathrm{abA}$ & $69,11 \mathrm{~A}$ \\
Guarani & $62,80 \mathrm{bC}$ & $67,33 \mathrm{bB}$ & $69,73 \mathrm{~A}$ \\
\hline
\end{tabular}

Médias seguidas de letras diferentes, minúscula na coluna e maiúscula na linha, diferem estatisticamente, pelo teste de Tukey a $5 \%$. L1 - Kc de 0,2 na fase vegetativa, na fase reprodutiva o inicial de 0,35 e o final de 0,50 e na fase de maturação o inicial de 0,50 e final de 0,35. L2 - o dobro do Kc de L1.

Tabela 5 - Desdobramento da interação preparo do solo $\mathrm{x}$ lâmina de água da análise de variância referente ao rendimento de benefício (\%). 1997/98.

\begin{tabular}{lccc}
\hline \multirow{2}{*}{ Preparo do solo } & \multicolumn{3}{c}{ Lâmina de água } \\
\cline { 2 - 4 } & Sequeiro & L1 & L2 \\
\hline Aiveca & $61,87 \mathrm{bB}$ & $68,85 \mathrm{~A}$ & $69,59 \mathrm{~A}$ \\
Escarificador & $65,20 \mathrm{aA}$ & $69,06 \mathrm{~A}$ & $70,13 \mathrm{~A}$ \\
Grade & $64,42 \mathrm{aB}$ & $68,39 \mathrm{~A}$ & $68,58 \mathrm{~A}$ \\
\hline
\end{tabular}

Médias seguidas de letras diferentes, minúscula na coluna e maiúscula na linha, diferem estatisticamente, pelo teste de Tukey a $5 \%$. L1 - Kc de 0,2 na fase vegetativa, na fase reprodutiva o inicial de 0,35 e o final de 0,50 e na fase de maturação o inicial de 0,50 e final de 0,35. L2 - o dobro do Kc de L1. 
de água utilizadas. Quanto à lâmina de água dentro de cultivar, observou-se efeito significativo apenas para os cultivares IAC 201 e Carajás onde as lâminas L1 e L2 apresentaram menor percentagem de grãos quebrados em relação ao sequeiro evidenciando a importância da irrigação por aspersão na melhoria da qualidade do produto colhido. É importante ressaltar que nas condições de sequeiro a cultura pode ter deficiência hídrica em períodos críticos de seu desenvolvimento e produção, entre estes, o da formação dos grãos. Assim a irrigação com as aplicações das lâminas L1 e L2 conseguiram suprir a cultura com água no período de formação dos grãos enquanto que no caso do sequeiro a deficiência hídrica provocou perda de qualidade. 0 arroz de sequeiro apresenta, em geral além da baixa produtividade, qualidade inferior quando comparado com o grão oriundo da cultura irrigada por inundação (Sant'Ana, 1989). A maior causa desse problema, além dos fatores atribuídos à genética do material, se relaciona com freqüentes períodos de deficiência hídrica que a planta sofre durante o ciclo.

A porcentagem de grãos chochos e gessados aumenta em muito quando a deficiência hídrica ocorre durante as fases de emissão da panícula e enchimento dos grãos. Dessa forma, a falta de água no cultivo de sequeiro é um fator importante que pode influenciar na qualidade física do grão, onde a sua formação inadequada e a presença de grãos gessados propiciam a ocorrência de uma maior porcentagem de grãos quebrados.

Tabela 6 - Desdobramento da interação cultivar x lâmina de água da análise de variância referente ao rendimento de inteiros (\%). 1997/98.

\begin{tabular}{lccc}
\hline \multirow{2}{*}{ Cultivar } & \multicolumn{3}{c}{ Lâmina de água } \\
\cline { 2 - 4 } & Sequeiro & L1 & L2 \\
\hline IAC 201 & $31,16 \mathrm{C}$ & $38,42 \mathrm{bB}$ & $45,49 \mathrm{abA}$ \\
Carajás & $33,01 \mathrm{~B}$ & $51,59 \mathrm{aA}$ & $50,85 \mathrm{aA}$ \\
Guarani & $31,81 \mathrm{~B}$ & $36,14 \mathrm{bAB}$ & $41,81 \mathrm{bA}$ \\
\hline
\end{tabular}

Médias seguidas de letras diferentes, minúscula na coluna e maiúscula na linha, diferem estatisticamente, pelo teste de Tukey a $5 \%$. L1 - Kc de 0,2 na fase vegetativa, na fase reprodutiva o inicial de 0,35 e o final de 0,50 e na fase de maturação o inicial de 0,50 e final de 0,35. L2 - o dobro do Kc de L1.

Tabela 7 - Desdobramento da interação cultivar x lâmina de água da análise de variância referente aos grãos quebrados (\%). 1997/98.

\begin{tabular}{lccc}
\hline \multirow{2}{*}{ Cultivar } & \multicolumn{3}{c}{ Lâmina de água } \\
\cline { 2 - 4 } & Sequeiro & $\mathrm{L} 1$ & $\mathrm{~L} 2$ \\
\hline IAC 201 & $35,04 \mathrm{aA}$ & $31,63 \mathrm{aA}$ & $23,95 \mathrm{aB}$ \\
Carajás & $29,42 \mathrm{bA}$ & $17,31 \mathrm{bB}$ & $18,22 \mathrm{bB}$ \\
Guarani & $30,94 \mathrm{ab}$ & $31,09 \mathrm{a}$ & $27,31 \mathrm{a}$ \\
\hline
\end{tabular}

Médias seguidas de letras diferentes, minúscula na coluna e maiúscula na linha, diferem estatisticamente, pelo teste de Tukey a $5 \%$. L1 - Kc de 0,2 na fase vegetativa, na fase reprodutiva o inicial de 0,35 e o final de 0,50 e na fase de maturação o inicial de 0,50 e final de 0,35 . L2 - o dobro do Kc de L1.

\section{CONCLUSÕES}

O cultivar IAC 201 apresenta maior rendimento de benefício e o Carajás destaca-se dos demais em rendimento de inteiros.

Os diferentes sistemas de preparo do solo utilizados praticamente não interferem no rendimento de engenho.

A irrigação por aspersão aumenta o rendimento de benefício e o rendimento de inteiros, principalmente em ano de ocorrência de veranico.

\section{REFERÊNCIAS BIBLIOGRÁFICAS}

ARF, O. Efeito de densidade populacional e adubação nitrogenada sobre o comportamento de cultivares de arroz irrigado por aspersão. Ilha Solteira, 1993. 63p. Tese (Livre-Docência) - Faculdade de Engenharia, Universidade Estadual Paulista "Júlio de Mesquita Filho".

ARF, O.; RODRIGUES, R.A.F.; SÁ, M.E.; CRUSCIOL, C.A.C.; BUZETTI, S. Influência da época de semeadura no comportamento de cultivares de arroz (Oryza sativa L.) irrigado por aspersão na região de Selvíria, MS. In: REUNIÃO NACIONAL DE PESQUISA DE ARROZ, 6., Goiânia. Anais. Goiânia: EMBRAPA, CNPAF, 1998. p.40-42.

BAZONI, R.; COSTA, C.A.; ARF, O.; MORAES, O.P.; SANTANA, E.P.; MOURA NETO, F.P.; PITOL, C. Recomendações de cultivares de arroz de sequeiro para o ano agrícola 1995/96, em Mato Grosso do Sul. Campo Grande: EMPAER-MS, 1995. (Comunicado Técnico, 17).

CENTRO INTERNACIONAL DE AGRICULTURA TROPICAL. Evaluacion de la calidad del arroz. Cali: CIAT, 1980. 22p.

CRUSCIOL, C.A.C.; MACHADO, J.R.; ARF, O.; RODRIGUES, R.A.F. Rendimento de benefício e de grãos inteiros em função do espaçamento e da densidade de semeadura do arroz de sequeiro. Scientia Agricola, v.56, p.47-52, 1999.

CRUSCIOL, C.A.C. Crescimento radicular, nutrição e produção de cultivares de arroz de terras altas em função da disponibilidade hídrica e de fósforo. Botucatu, 2001. 111p. Tese (Livre Docência) - Faculdade de Ciências Agrárias, Universidade Estadual Paulista "Júlio de Mesquita Filho.

DOORENBOS, J.; KASSAN, A.H. Efectos del agua en el rendimiento de Ios cultivos. Roma: FAO, 1979. 212p. (Riego y Drenage, 33)

DOORENBOS, J.; PRUITT, W.O. Las necesidades de agua de los cultivos Roma: FAO, 1976. 194p. (Riego e Drenage, 24).

GROHMANN, F. Distribuição e tamanho de poros em três tipos de solos do Estado de São Paulo. Bragantia, v.21, p.285-295, 1960.

KUNZE, O.R. Effect of enviroment and variety on milling qualities of rice. In: INTERNATIONAL RICE RESEARCH INSTITUTE. Rice grain quality and marketing. Manila, 1985. p.37-45.

NAKAO, W. Manejo de água na cultura do arroz (Oryza sativa L.) irrigado por aspersão. Ilha Solteira, 1995. 44p. Monografia (Graduação) - Faculdade de Engenharia, Universidade Estadual Paulista "Júlio de Mesquita Filho".

OLIVEIRA, G.S. Efeito de densidade de semeadura no desenvolvimento de cultivares de arroz (Oryza sativa L.) em condições de sequeiro irrigado por aspersão. Ilha Solteira, 1994. 41p. Monografia (Graduação) - Faculdade de Engenharia, Universidade Estadual Paulista "Júlio de Mesquita Filho".

OLIVEIRA, G.S.; ARF, O.; SÁ, M.E.; RODRIGUES, R.A.F. Efeito de densidades de semeadura no desenvolvimento de cultivares de arroz (Oryza sativa L.) em condições de sequeiro e de irrigação por aspersão. I. Características Agronômicas. Científica, v.25, p.67-83, 1997.

OLIVEIRA, G.S.; ARF, O.; SÁ, M.E.; RODRIGUES, R.A.F. Efeito de espaçamentos e densidades de semeadura sobre o desenvolvimento de cultivares de arroz de sequeiro irrigado por aspersão. II. Componentes do rendimento de engenho. In: REUNIÃO NACIONAL DE PESQUISA DE ARROZ, 6., Goiânia. Anais. Goiânia: EMBRAPA, CNPAF, 1998. p.49-52.

RAIJ, B. van; QUAGGIO, J.A. Métodos de análise de solo para fins de fertilidade. Campinas: Instituto Agronômico, 1983. 31p. (Boletim Técnico, 81).

RAIJ, B. van; CANTARELLA, H.; QUAGGIO, J.A.; FURLANI, A.M.C. Recomendações de adubação e calagem para o Estado de São Paulo. 2.ed. Campinas: Instituto Agronômico, 1996. 285p. (Boletim Técnico, 100)

RICHARDS, L.A. Pressure membrane apparatus construction and use. Agricultural Engineering, v.28, p.451-454, 1947.

RICHARDS, L.A.; FIREMAN, M. Pressure - plate apparatus for measuring moisture sortin and transmission by soils. Soil Science, v.56, p.395-404, 1943.

SANT'ANA, E.P. Cultivo de arroz irrigado por aspersão. Informe Agropecuário, v.14, p.71-75, 1989.

ZARATIN, C. Efeitos de doses e do parcelamento potássico sobre a produção e qualidade de sementes em quatro cultivares de arroz. Ilha Solteira, 2000. 79p. Monografia(Graduação) - Faculdade de Engenharia, Universidade Estadual Paulista "Júlio de Mesquita Filho".

Recebido em 28.11.00 